\title{
A minireview on phytochemical and medicinal properties of Clinacanthus nutans
}

\author{
Peik Lin Teoh* \\ Biotechnology Research Institute, Universiti Malaysia Sabah, Jalan UMS, 88400 Kota Kinabalu, Malaysia.
}

\author{
ARTICLE INFO \\ Received on: 02/11/2020 \\ Accepted on: 16/01/2021 \\ Available online: 05/06/2021 \\ Key words: \\ Clinacanthus nutans, \\ ethnobotanical uses, \\ phytochemical constituents, \\ medicinal properties, toxicity.
}

\begin{abstract}
Clinacanthus nutans (Burm.f.) Lindau has attracted considerable attention in the past two decades, particularly in Southeast Asia, due to its medicinal properties. It has broadly been used as a folk medicine to treat various illnesses ranging from snake bites, viral infection, inflammation, diabetes, and cancers. Natural phytochemical constituents isolated from this plant possess medicinal properties that can help maintain general health and prevent or treat certain diseases. This paper aims to provide an updated overview of its ethnomedicinal uses, phytochemical constituents, pharmacological activities, and toxicity.
\end{abstract}

\section{INTRODUCTION}

Despite tremendous advancement in therapeutic intervention, plant-based traditional medicines remain popular worldwide for treating various ailments. Medicinal plants represent a vast reservoir of bioactive molecules that are invaluable for treating a broad spectrum of diseases and promising sources for discovering interesting compounds for therapeutic intervention. Nevertheless, only about $15 \%$ of plant species have been thoroughly studied for their potential medicinal values (Süntar, 2020).

Clinacanthus nutans (Burm. f) Lindau is a perennial plant belonging to the family of Acanthaceae. The synonyms of $C$. nutans are Clinacanthus burmanni Nees, Justicia nutans (Burm. f), and C. nutans var. robinsonii Benoist (Aslam et al., 2014). It is widely found in Asian nations including Indonesia, Malaysia, Thailand, Vietnam, and China (Arullappan et al., 2014). In Malaysia, it is also recognized as "Belalai Gajah" in Malay, Sabah Snake Grass, and "You Dun Cao" or "E zui hua" in Mandarin. It has various vernacular names such as "Ki Tajam (Sundal),"

\section{"Corresponding Author}

Peik Lin Teoh, Biotechnology Research Institute, Universiti Malaysia Sabah, Kota Kinabalu, Malaysia.E-mail:peiklin@ums.edu.my and "Saled Pangpon Tua Mea" (Saliva of the female mongoose) in Thailand, and "Gendis" and "Dandang Gendis" in Indonesia (Aslam et al., 2014; Zulkipli et al., 2017).

Clinacanthus nutans can grow up to $1 \mathrm{~m}$ in height with cylindrical, striate, and hairless stems (Fig. 1). The stems are small, soft, thin, and slightly curved, resembling an elephant trunk. The leaves are simple, opposite to its leaf blade narrowly elliptic and oblong or lanceolate shapes. Its leaf surface is pubescent when young and becomes glabrescent at maturity. The flowers are yellowish and are formed in clusters at the top branches and branchlets (Shim et al., 2013; Yahaya et al., 2015).

\section{Ethnobotanical uses}

Clinacanthus nutans is a well-known folk medicine, especially in Thailand and Malaysia. It has reportedly been used for various ailments such as snake bites, viral infection [herpes simplex viruses (HSV-1 and HSV-2), varicella-zoster virus (VZV), and human papillomavirus (HPV)], and cancer (Kamarudin et al., 2017; Kongkaew and Chaiyakunapruk, 2011; Kunsorn et al., 2013). Apart from that, C. nutans extracts are also useful in treating inflammation disorders such as swelling, bruises, strains, sprains of injuries, and rheumatism. It has also been used for gastrointestinal diseases, dysuria, diabetes, fever, and regulating the menstrual cycle (Shim et al., 2013). 


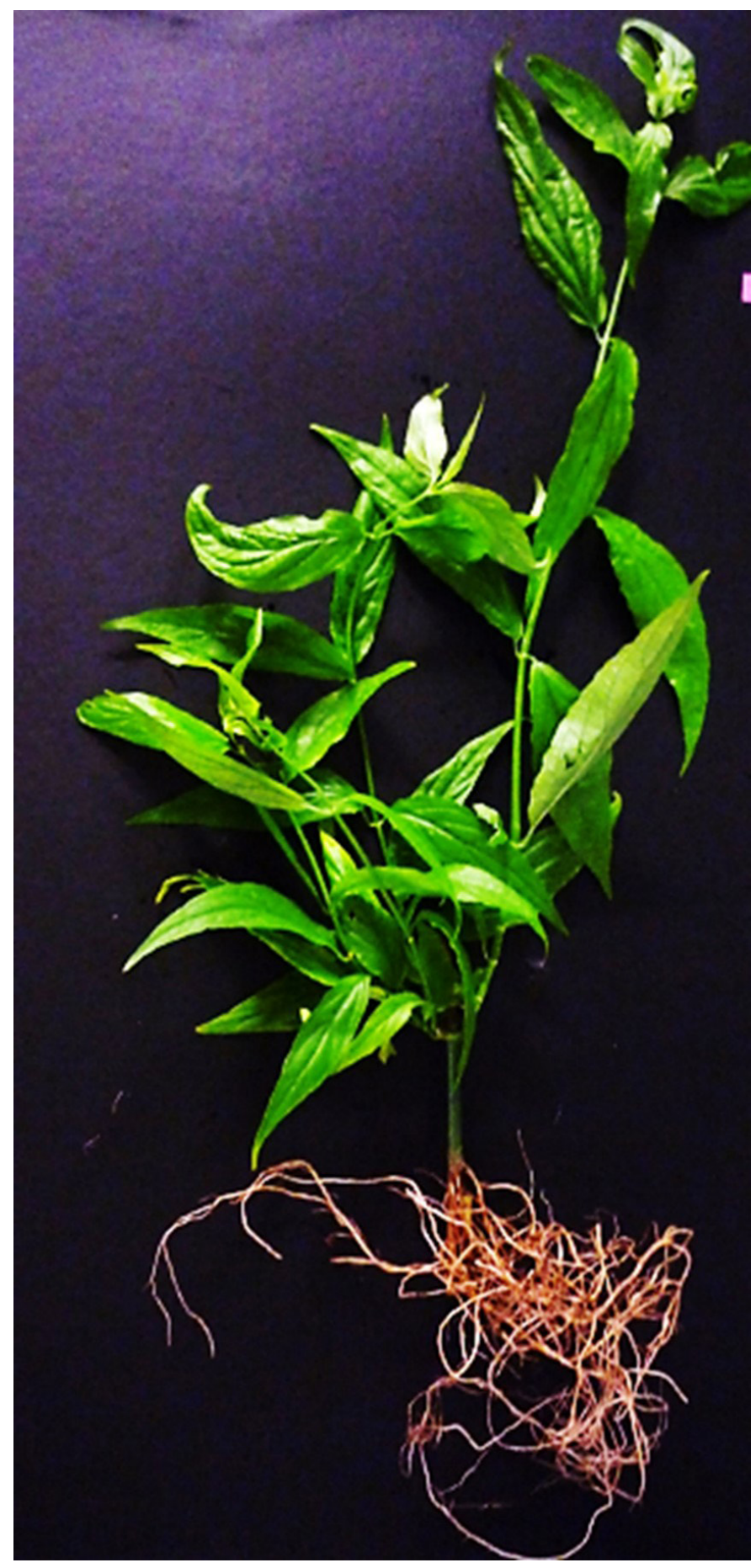

Figure 1. Clinacanthus nutans.

Its fresh leaves are commonly served alone or together with herbs as tea because of their nutritional and antioxidant properties. Besides that, it is also used as a home remedy for cancer patients. In Thailand, the alcoholic extract was applied externally for skin irritations, snake/insect bites, and lesions caused by HSV and VZV (Sakdarat et al., 2009). The leaves could be consumed alone or mixed with other juices (Aslam et al., 2014) for general well-being. The combination of leaves and stem was also used to make an infusion or decoction to treat hepatitis infection (Teshima et al., 1998). The lotions and creams made solely from the plant had been reported by Sakdarat et al. (2006) to treat minor skin inflammation and insect bites.

In Malaysia, cancer patients have claimed their recovery from cancer illnesses after drinking a decoction made from $C$. nutans leaves over a certain period. Currently, various testimonies asserted the effectiveness of this herb for different cancer treatments and prevention. Due to the lack of scientific study and evidence, tremendous efforts have been invested in understanding and deciphering the molecular interactions of the phytochemical compounds and their molecular targets in the last few decades.

\section{Chemical constituents}

Extraction, isolation, and characterization of phytochemicals from various parts of $C$. nutans revealed a wide range of bioactive compounds. It consists of lupeol, stigmasterol, $\beta$-sitosterol, betulin, and myricyl alcohol (Arullappan et al., 2014; Charuwichitratana et al., 1996; Chavalittumrong et al., 2013; Dampawan et al., 1977; Teoh et al., 2017). Six C-glycosyl flavones such as orientin, isoorientin, isomollupentin 7-O-bglucopyranoside, schaftoside, isovitexin, and vitexin had been isolated from the butanol and water extracts of this plant. The butanol fraction was found to have five sulfur-containing glucosides: clinacoside A, clinacoside $\mathrm{B}$, clinacoside $\mathrm{C}$, and cycloclinacoside A1 (Teshima et al., 1998). Moreover, its hexane and chloroform leaf extracts possessed chemical constituents such as 13-hydroxy-(13-S)-phaeophytin b, pupurin-18-phytyl ester, and pheophorbide (Ayudhya et al., 2001). A few phaeophytins, chlorophyll derivatives, namely, $13^{2}$-hydroxy-(132-R)-phaeophytin b, $13^{2}$-hydroxy-(132-S)-phaeophytin a, and $13^{2}$-hydroxy- $\left(13^{2}-\right.$ R)-phaeophytin a, were also found in the chloroform extracts (Sakdarat et al., 2009). These compounds have shown potent antiviral activities, particularly against HSV by affecting viral entry into host cells.

Satakhun et al. (2001) had reported two glycogly cerolipid compounds (1-O-palmitoyl-2-Olinolenoyl-3-O-[ $\alpha-\mathrm{D}$ galactopyranosyl-(1"6')-O- $\beta$-D-galacctopyranosyl]-glycerol and 1,2-Odilinolenoyl-3-O- $\beta$-D-galactopyranosyl-glycerol) from the leaves. Nine cerebrosides and a monoacylmonogalactosylglycerol were isolated in the leaf ethyl acetate fraction (Tuntiwachwuttikul et al., 2004). An antimicrobial compound, known as 1,2-benzene dicarboxylic acid, mono(2-ethylhexyl) ester, was isolated from the chloroform leaf extract (Yong et al., 2013). Besides having phenolic compounds such as gallic and caffeic acids, the methanol leaf extracts also have flavonoids constituents like catechin and kaempferol (Ghasemzadeh et al., 2014).

Chemical constituents with the established biological functions or potential therapeutic benefits are summarized in Table 1. Phytochemicals such as catechin, betulin, lupeol, kaempferol, squalene, and vitamin $\mathrm{E}$ are known to possess antioxidant, anticancer, and anti-inflammatory activities. Molecular docking analysis has predicted several bioactive compounds that could potentially be used in preventing disorders linked to hyperuricemia, wound healing, and hyperlipidemia. Among them were clinacoside A-C, cycloclinacoside A1, shaftoside, vitexin, orientin, isovitexin, and isoorientin (Narayanaswamy et al., 2016) 
Table 1. Phytochemical compounds found in C. nutans with known biological functions.

\begin{tabular}{|c|c|c|}
\hline Plant part & Chemical constituent & References \\
\hline Stem and root & Lupeol & Dampawan et al. (1977), Teoh et al. (2017) \\
\hline Leaf and root & Stigmasterol & $\begin{array}{l}\text { Charuwichitratana et al. (1996), Teoh et al. (2017); } \\
\text { Haron et al. (2019) }\end{array}$ \\
\hline Leaf, stem and root & $\beta$-sitosterol & Arullappan et al. (2014); Teoh et al. (2017) \\
\hline Root & Betulin, squalene & Teoh et al. (2017) \\
\hline Leaf and stem & $\begin{array}{l}\text { Orientin, isoorientin, isomollupentin 7-O-b-glucopyranoside, schaftoside, isovitexin, } \\
\text { vitexin, clinacoside } \mathrm{A} \text {, clinacoside } \mathrm{B} \text {, clinacoside } \mathrm{C} \text {, cycloclinacoside } \mathrm{A} 1\end{array}$ & Teshima et al. (1998) \\
\hline \multirow[t]{8}{*}{ Leaf } & Myricyl alcohol & Chavalittumrong et al. (2013) \\
\hline & 1,2-Odilinolenoyl-3-O- $\beta$-D-galactopyranosyl-glycerol & Satakhun et al. (2001) \\
\hline & 1,2-benzenedicarbox-ylic acid, mono(2-ethylhexyl) ester & Yong et al. (2013) \\
\hline & Gallic acid, caffeic acid & Ghasemzadeh et al. (2014), Rahim et al. (2016) \\
\hline & Catechin, kaempferol & Ghasemzadeh et al. (2014) \\
\hline & Protocatechuic acid, cinnamic acid, chlorogenic acid, ferulic acid & Sarega et al. (2016a) \\
\hline & Vitamin E, phytol & Haron et al. (2019) \\
\hline & Myricetin, orientin, isoorientin, vitexin, isovitexin, isookanin, apigenin, ferulic acid & Aliyu et al. (2020) \\
\hline
\end{tabular}

\section{Pharmacological activities}

Traditionally, C. nutans is a folk medicine for alleviating various health complications and ailments. In Thailand, numerous studies have shown that $C$. nutans leaf extracts exhibited excellent biological activities against viruses, inflammation, and cancer. In clinical trials, creams blended with the plant extract showing positive effects in alleviating patients with HSV and VZV infections (Charuwichitratana et al., 1996). Other studies also discovered that the medicinal products from this plant had replaced acyclovir topical to treat herpes simplex and herpes zoster in hospitals (Kongkaew and Chaiyakunapruk, 2011; Vachirayonstien et al., 2010).

Sriwanthana et al. (1996) stated that C. nutans was traditionally used in cancer patients as primary complementary or alternative herbal remedies. In Thailand, the aerial parts of the plant prepared in decoction form showed an anticancer effect on KB cells (human nasopharyngeal carcinoma cell line) and mammary cancer-bearing rats by promoting the activity of natural killer cells (Na-Bangchang et al., 2012). People in Malaysia also have the same practice where they mixed $C$. nutans leaf in various formulations such as herbal or fruit juices. Many of them claimed to have recovered after using it for a certain period (P'ng et al., 2013). Thus, attempts to understand its modes of action are carried out mainly using $C$. nutans leaf extracts.

Despite controversial findings, some research findings revealed the chemoprevention and chemotherapy potential of $C$. nutans. For instance, the aqueous extract was found to possess significant antiproliferative activity against cervical cancer (HeLa) and erythroleukemia (K-562), while the chloroform extract showed profound inhibitory effects against K-562 and Raji cells (Yong et al., 2013). However, only Teoh et al. (2017) demonstrated its root extracts to exhibit antiproliferative and proapoptotic activities on breast cancer cell line, MCF-7.

Apart from that, its ethanol leaf extracts were also shown to have protective effects of DNA integrity by retaining the supercoiled structure of plasmid DNA under riboflavin photoreaction treatment (Yuann et al., 2012). Besides that, the leaf extract also elicited antioxidant activity and prevented the rupture of red blood cells induced by free radicals (Pannangpetch et al., 2007).
Male mice repeatedly administrated with the leaf methanol extracts at different concentrations of 250,500, and 1,000 $\mathrm{mg} / \mathrm{kg}$ for 14 days continuously showed a significant increase of acetylcholinesterase (AChE) activity in several organs (e.g., heart, liver, and kidney) but not in the brain. This indicated that the extract did not cause neurological dysfunctions in the treated mice (Lau et al., 2014). However, the bioactive compounds that contribute to the activation of AChE remain unknown.

The only polysaccharide-peptide complex reported so far was isolated from the leaves. It was made of $87.25 \%$ carbohydrate and $9.37 \%$ protein. This complex inhibited the growth of gastric cancer cells (SGC-7901) in a concentrationdependent manner. It also increased the nitric oxide production in RAW264.7 cells, suggesting an immunomodulating effect (Huang et al., 2016).

The metabolomic findings on $C$. nutans aqueous extracts at the concentrations of 500 and $1,000 \mathrm{mg} / \mathrm{kg}$ ameliorated the physiological sickness behavior in lipopolysaccharide-induced rats after 2 weeks. This improvement was correlated with antineuroinflammatory metabolite biomarkers' expression from nuclear magnetic resonance spectra compared to the sera obtained from the control group (Azam et al., 2019). Additional and updated studies supporting the pharmacological actions of C. nutans are deliberated and depicted in Table 2.

\section{Toxicity}

Several toxicological assessments of $C$. nutans extracts have been carried out on animals, but no lethal toxicity was reported so far. P'ng et al. (2013) observed no lethality and abnormal behavior in mice administrated with the methanolic leaf extracts $(300,600$ and $900 \mathrm{mg} / \mathrm{kg})$ for up to 14 days. Both treated and control groups showed no significant differences in terms of serum biochemical tests. In another study, the subchronic toxicity of the ethanol leaf extract was assessed in male Sprague Dawley rats for 90 days (Asyura et al., 2016). The results demonstrated hepatotoxicity and renal toxicity with no mortality in rats treated with $125-250 \mathrm{mg} / \mathrm{kg}$ of plant extracts. Conversely, Roslan et al. (2017) documented subacute toxicities in the female BALB/c 
Table 2. The pharmacological activities of C. nutans.

Plant parts and extracts
Whole plant (methanol extract)
Leaf (ethanol)
Leaf (hexane, dichloromethane and
methanol extracts)
Leaf (methanol extract)
Leaf (chloroform extract)
Leaf (ethanol extract)
Aerial part (ethanol extract)
Leaf and stem (petroleum ether and ethyl
acetate)
Leaf (methanol extract)
Leaf (methanol extract)
Leaf (ethanol and ethyl acetate extracts)
Aerial part (ethanol extract)

Leaf (methanol extract)

Leaf (methanol extract)

Leaf (ethanol extract

Leaf (water and methanol extracts)

Leaf and stem (polar extract)

Leaf (aqueous extract)

Root (methanol and ethyl acetate extracts)

Leaf and stem (chloroform and hexane extracts)

Leaf (methanol extract)

Pharmacological activities

Suppressed ethyl phenylpropiolate-induced ear edema and carrageenan-induced paw edema in dose-dependent manner.

Exhibited antioxidant activity by protecting the plasmid DNA from riboflavin photoreaction.

Possessed antiviral activities against HSV-1 and HSV-2.

Showed antibacterial activity against Staphylococcus aureus and Escherichia coli.

Exhibited antiproliferative effects on various human cancer cells such as erythroleukemia (K-562), liver hepatocellular carcinoma (HepG2), lung (NCI-H23), gastric (SNU-1), colon adenocarcinoma (LS-174T), cervical (HeLa) and Burkitt's lymphoma (Raji); but no effect on neuroblastoma (IMR-32) and normal human umbilical vein endothelial cells (HUVECs).

In vitro studies showed that keratinocyte cells (HaCat) were protected from IFN- $\gamma / \mathrm{TNF}-\alpha$ induced apoptosis.

Four new compounds (clinamides A-C and 2-cis-entadamide A) were isolated from ethanol extract but none of them showed anti-inflammatory, immunomodulating and anti-dengue virus activities.

Both petroleum ether leaf and stem extracts and ethyl acetate stem extract inhibited the growth of HeLa cells.

Increased AChE activity in liver, kidney and heart but not in the brain of male mice. No neurological disorder was observed.

Inhibited the growth of triple negative breast cancer cell line, MDA-MB-231.

Both extracts showed growth inhibitory effects on breast cancer cell line, MCF-7.

References

Wanikiat et al. (2008)

Yuann et al. (2012)

Kunsorn et al. (2013)

Ho et al. (2013)

Yong et al. (2013)

Thongrakard and Tencomnao (2013)

Tu et al. (2014)

Arullappan et al. (2014)

Lau et al. (2014)

Nasir and Bohari (2015)

Sulaiman et al. (2015)

Inhibited hepatoma xenograft in mice by increasing the expression of proapoptotic protein while downregulating Huang et al. (2015) proliferating cell nuclear antigen (PCNA) and phosphor-protein kinase B (p-AKT). Immunomodulating activity was evidenced through the increase of IFN- $\gamma$ and IL-2 in serum.

Induced apoptosis in human melanoma cells (D24).

Fong et al. (2016)

Exerted central and peripheral antinociceptive activity through the activation of opioid receptor and nitric oxide mediated pathway. However, it is cyclic guanosine monophosphate (cGMP)-independent.

Exhibited neuroprotective effects on astrocytes and endothelial cells under hypoxic condition by downregulating histone deacetylases (HDAC1/6).

Showed termination of hyperlipidemia-associated oxidative stress in rats by increasing the antioxidant enzymes activity and expression of antioxidant genes in serum and liver.

Prevented insulin resistance by upregulating of insulin receptor, phosphotidyl inositol-3-phosphate, adiponectin receptor and leptin receptor genes in rats fed with high fat and high cholesterol diet.

Showed anti-inflammatory effect by inactivating the cytokine production and Toll-Like receptor-4 in lipopolysaccharides-induced RAW264.7 cells.

Exhibited anti-cancer effects on human cervical cancer cells (HeLa) while normal kidney cell line (Vero) was not inhibited.

Promoted apoptosis by suppressing BCL-2 in MCF-7 cells via mitochondria-dependent or independent pathway.

Exhibited antiproliferative effects on non-small cell lung cancer (A549), nasopharygeal cancer (CNE1) and liver cancer (HepG2) cell lines. Hexane extract induced sub-G1 phase arrest and apoptosis via oxidative stress. At high concentrations ( $>100 \mu \mathrm{g} / \mathrm{ml}$ ), the upregulation of caspases 8,9 and $3 / 7$ was observed.

Cytotoxic effects were found in various cancer cell lines such as Hep-G2, A549, HT-29, MDA-MB-231, MCF-7, and CRL 1739. Cytochrome P450 inhibitory (CYP3A4 \& CYP2E1) activities were also reported in human liver microsomes.

Exhibited anti-angiogenic activities in endothelial cells.

Showed antimicrobial properties against pathogenic microorganisms.

Inhibited lymphoma SUP-T1 cells by inducing apoptosis through the loss of mitochondrial membrane potential. Besides increases of reactive oxygen species (ROS) and calcium ion, the upregulation of CHOP and IRE-1 $\alpha$ proteins (ER stress) was also observed.

Sonicated water extract had the highest nitric oxide inhibitory effect in lipopolysaccharide-interferon-gammainduced RAW264.7 macrophages. ${ }^{1} \mathrm{H}-\mathrm{NMR}$ metabolomic analysis suggested C-glycosyl flavones abundantly found in this extract plays an important role in anti-inflammatory effect.

Decreased nitric oxide and malondialdehyde levels in blood in mice treated with $200 \mathrm{mg} / \mathrm{kg}$ and $1,000 \mathrm{mg} /$ $\mathrm{kg}$ of leaf extract. Mitotic cells, tumor weight, and tumor volume were reduced. No inflammatory and adverse reactions related to splenocytes activities were found in all treated mice.

Dichloromethane extract inhibited the proliferation of cervical cancer by inducing apoptosis and cell cycle arrest.

Hexane and dichloromethane extracts showed better cytotoxicity effects on MCF-7 but the dichloromethane extract exhibited less inhibitory effect on normal breast cells. Through molecular docking, palmitic acid and linolenyl alcohol in dichloromethane extract were found to have the highest binding affinity with p53-binding protein Mdm-2.
Rahim et al. (2016)

Tsai et al. (2016)

Sarega et al. (2016a)

Sarega et al. (2016b)

Mai et al. (2016)

Zakaria et al. (2017)

Teoh et al. (2017)

Ng et al. (2017)

Quah et al. (2017)

$\mathrm{Ng}$ et al. (2018)

Kong and Abdullah Sani (2018)

Lu et al. (2018)

Khoo et al. (2019)

Haron et al. (2019)

Nik Abd Rahman et al. (2019)

Ismail et al. (2020) 
mice organs after administering 300, 2,000 and 5,000 mg/kg of the ethanol leaf extract for 28 days.

The $C$. nutans methanolic leave extract showed adverse effects on the CYP3A4 enzyme activity of human liver microsomes. If the plant extract is consumed together with a drug metabolized by CYP3A4, it can slow down xenobiotics' metabolism in the body. The xenobiotic accumulation for extended periods may become potentially toxic in the body system (Quah et al., 2017). It was also found that the male and female mice showed no alteration of their body weight after administrated with the methanolic leaf extracts at 1,000 and $2,000 \mathrm{mg} / \mathrm{kg}$. Besides, there were no hematological, biochemical, and histology signs of toxicity after 28 days (Abdulwahid et al., 2018).

The metabolomic analysis carried out using highresolution proton nuclear magnetic resonance ( $\left.{ }^{1} \mathrm{H}-\mathrm{NMR}\right)$ on the acute toxicity of rats administrated with a single dose of leaf water extract at $5,000 \mathrm{mg} / \mathrm{kg}$ for 15 days did not show significant metabolic abnormalities. These findings were in accordance with the results derived from physical, hematological, biochemical, and histopathological observation (Khoo et al., 2018).

On the contrary, Aliyu et al. (2020) suggested that precautions should be taken if they intend to use the plant extract as a health supplement after observing hepatic and kidney toxicities in mice continuously consumed with $C$. nutans ethanolic leaf extract $(1,000 \mathrm{mg} / \mathrm{kg})$ for up to 28 days. Besides, a single dose at $2,000 \mathrm{mg} / \mathrm{kg}$ could also cause mild histological changes in the liver and renal with no hematological toxicity.

\section{CONCLUSION}

Even though extensive research has managed to shed light on the potential therapeutic values of $C$. nutans, scientific evidence is still scarce. For instance, many studies, including clinical trials, have shown a promising effect on antiviral activities, but its underlying molecular mechanisms are still unclear. More research focusing on multiple signaling pathways instead of targeting specific biological action will provide a better understanding of how these bioactive compounds exert their biological functions. Further investigations on the chronic toxicity effects of $C$. nutans plant extract also need to be done to ensure its safe consumption. These comprehensive data are essential in facilitating the discovery of potential drug target(s) and future development of $\operatorname{drug}(\mathrm{s})$ derived from $C$. nutans.

\section{ACKNOWLEDGMENTS}

The author thanks Dr. Bonaventure Vun Leong Wan for proofreading the manuscript, Dr. Cheong Bo Eng for providing the photo, and Universiti Malaysia Sabah for the support.

\section{AUTHOR CONTRIBUTIONS}

All authors made substantial contributions to conception and design, acquisition of data, or analysis and interpretation of data; took part in drafting the article or revising it critically for important intellectual content; agreed to submit to the current journal; gave final approval of the version to be published; and agree to be accountable for all aspects of the work. All the authors are eligible to be an author as per the international committee of medical journal editors (ICMJE) requirements/guidelines.

\section{CONFLICTS OF INTEREST}

The authors report no financial or any other conflicts of interest in this work.

\section{ETHICAL APPROVALS}

This study does not involve experiments on animals or human subjects.

\section{PUBLISHER'S NOTE}

This journal remains neutral with regard to jurisdictional claims in published institutional affiliation.

\section{REFERENCES}

Abdulwahid SJ, Goh MY, Ebrahimi M, Mohtarrudin N, Hashim Z. Sub-acute oral toxicity profiling of the methanolic leaf extract of Clinacanthus nutans in male and female ICR mice. Int J Pharm Pharm Sci, 2018; 10(12):25-35.

Aliyu A, Shaari MR, Sayuti NSA, Reduan MFH, Sithambaram S, Noordin MM, Shaari K, Hamzah H. Subacute oral administration of Clinacanthus nutans ethanolic leaf extract induced liver and kidney toxicities in ICR mice. Molecules, 2020; 25(11):2631.

Arullappan S, Rajamanickam P, Thevar N, Kodimani CC. In vitro screening of cytotoxic, antimicrobial and antioxidant activities of Clinacanthus nutans (Acanthaceae) leaf extracts. Trop J Pharm Res, 2014; 13(9):1455-61.

Aslam MS, Ahmad MS, Mamat AS. A review on phytochemical constituents and pharmacological activities of Clinacanthus nutans. Int J Pharm Pharm Sci, 2014; 7(2):30-3.

Asyura SNN, Hamzah H, Shaari RM, Sithambaram S, Mustapha NM. Blood profiles and histopathological changes of liver and kidney tissues from male sprague dawley rats treated with ethanol extracts of Clinacanthus nutans Leaf. J Clin Toxicol, 2016; 6:329.

Ayudhya TDN, Sakdarat S, Shuyprom A, Du an gpen Pattaraadilok JB, Waterman PG, Karagianis G. Chemical constituents of the leaves of Clinacanthus nutans lin-dau. Thai J Phytopharm, 2001; 8:1.

Azam AA, Ismail IS, Shaikh F, Shaari K, Abas F. Effects of Clinacanthus nutans leaf extract on lipopolysaccharide-induced neuroinflammation in rats: a behavioral and ${ }^{1} \mathrm{H}$ NMR-based metabolomics study. Avicenna J Phytomed, 2019; 9(2):164-86.

Charuwichitratana S, Wongrattanapasson N, Timpatanapong P, Bunjob M. Herpes zoster: treatment with Clinacanthus nutans cream. Int J Dermatol, 1996; 35(9):665-6.

Chavalittumrong P, Attawish A, Rugsamon P, Chuntapet P. Toxicological study of Clinacanthus nutans (Burm.f.) Lindau. Bull Dept Med Sci, 2013; 37:323-38.

Dampawan P, Huntrakul C, Reutrakul V, Raston CL, White AH. Constituents of Clinacanthus nutans and the crystal structure of lup-20(29)ene-3-one. J Sci Soc Thailand, 1977; 3(1):14-26.

Fong SY, Piva T, Dekiwadia C, Urban S, Huynh T. Comparison of cytotoxicity between extracts of Clinacanthus nutans (Burm. f.) Lindau leaves from different locations and the induction of apoptosis by the crude methanol leaf extract in D24 human melanoma cells. BMC Complement Altern Med, 2016; 16:368.

Ghasemzadeh A, Nasiri A, Jaafar HZE, Baghdadi A, Ahmad I. Changes in phytochemical synthesis, chalcone synthase activity and pharmaceutical qualities of Sabah Snake Grass (Clinacanthus nutans L.) in relation to plant age. Molecules, 2014; 19(11):17632-48.

Haron NH, Md Toha Z, Abas R, Hamdan MR, Azman N, Khairuddean M, Arsad H. In vitro cytotoxic activity of Clinacanthus nutans leaf extracts against HeLa cells. Asian Pac J Cancer, 2019; 20:601-9.

Ho SY, Tiew WP, Priya M, Abdul Shukkoor MS, Akowuah GA. Phytochemical analysis and antibacterial activity of methanolic extract of Clinacanthus nutans leaf. Int J Drug Dev Res, 2013; 5(3):349-55. 
Huang D, Guo W, Gao J, Chen J, Olatunji J. Clinacanthus nutans (Burm. f.) Lindau ethanol extract inhibits hepatoma in mice through upregulation of the immune response. Molecules, 2015; 20:17405-28.

Huang D, Li Y, Cui F, Chen J, Sun J. Purification and characterization of a novel polysaccharide-peptide complex from Clinacanthus nutans Lindau leaves. Carbohydr Polym, 2016; 137:701-8.

Ismail NZ, Md Toha Z, Muhamad M, Nik Mohamed Kamal NNS, Mohamad Zain NN, Arsad H. Antioxidant effects, antiproliferative effects, and molecular docking of Clinacanthus nutans leaf extracts. Molecules, 2020; 25(9):2067.

Kamarudin MNA, Sarkera MMR, Kadirb HA, Ming LC. Ethnopharmacological uses, phytochemistry, biological activities, and therapeutic applications of Clinacanthus nutans (Burm. f.) Lindau: a comprehensive review. J Ethnopharmacol, 2017; 206:245-66.

Khoo LW, Audrey Kow SF, Maulidiani M, Ang MY, Chew WY, Lee MT, Tan CP, Shaari K, Tham CL, Abas F. 'H-NMR metabolomics for evaluating the protective effect of Clinacanthus nutans (Burm. f) Lindau water extract against nitric oxide production in LPS-IFN- $\gamma$ activated RAW 264.7 macrophages. Phytochem Anal, 2019; 30(1):46-61.

Khoo LW, Kow ASF, Maulidiani M, Lee MT, Tan CP, Shaari K, Tham CL, Abas F. Hematological, biochemical, histopathological and ${ }^{1} \mathrm{H}-\mathrm{NMR}$ metabolomics application in acute toxicity evaluation of Clinacanthus nutans water leaf extract. Molecules, 2018; 23(9):2172.

Kong HS, Abdullah Sani N. Antimicrobial properties of the acetone leaves and stems extracts of Clinacanthus nutans from three different samples/areas against pathogenic microorganisms. Int Food Res J, 2018; 25(4):1698-702.

Kongkaew C, Chaiyakunapruk N. Efficacy of Clinacanthus nutans extracts in patients with herpes infection: Systematic review and meta-analysis of randomized clinical trials. Complement Ther Med, 2011; 19:47-53.

Kunsorn P, Ruangrungsi N, Lipipun V, Khanboon A, Rungsihirunrat $\mathrm{K}$. The identities and anti-herpes simplex virus activity of Clinacanthus nutans and Clinacanthus siamensis. Asian Pac J Trop Biomed, 2013; 3:284-90.

Lau K, Lee S, Chin J. Effect of the methanol leaves extract of Clinacanthus nutans on the activity of acetylcholinesterase in male mice. J Acute Dis, 2014; 3:22-5.

Lu MC, Li TY, Hsieh YC, Hsieh PC, Chu YL. Chemical evaluation and cytotoxic mechanism investigation of Clinacanthus nutans extract in lymphoma SUP-T1 cells. Environ Toxicol, 2018; 33(12):1229-36.

Mai CW, Yap KS, Kho MT, Ismail NH, Yusoff K, Shaari K, Chin SY, Lim ES. Mechanisms underlying the anti-inflammatory effects of Clinacanthus nutans Lindau extracts: inhibition of cytokine production and Toll-like receptor-4 activation. Front Pharmacol, 2016; 7:7.

Na-Bangchang K, Ketsa-ard K, Wiwatwittaya S, Thongprasert S, Vongsakul M, Picha P, Karbwang J. Anti-cancer activity and immunostimulating effect on NK-cell activity of a well-known Thai folkloric remedy. Int Res J Pharm Pharmacol, 2012; 2(10):254-64.

Narayanaswamy R, Isha A, Lam KW, Ismail IS. Molecular docking analysis of selected Clinacanthus nutans constituents as xanthine oxidase, nitric oxide synthase, human neutrophil elastase, matrix metalloproteinase 2, matrix metalloproteinase 9 and squalene synthase inhibitors. Pharmacogn Mag, 2016; 12(1):S21-6.

Nasir NAK, Bohari SPM. Cytotoxicity effects of Typhonium flagelliforme and Clinacanthus nutans on breast cancer cells. J Teknol, 2015; 77(31):45-50.

Ng CT, Fong LY, Tan JJ, Rajab NF, Abas F, Shaari K, Chan KM, Juliana F, Yong YK. Water extract of Clinacanthus nutans leaves exhibits in vitro, ex vivo and in vivo anti-angiogenic activities in endothelial cell via suppression of cell proliferation. BMC Complement Altern Med, 2018; $18: 210$

Ng PY, Chye SM, Ng CH, Koh RY, Tiong YL, Pui LP, Tan YH, Lim CS, Ng KY. Clinacanthus nutans hexane extracts induce apoptosis through a caspase-dependent pathway in human cancer cell lines. Asian Pac J Cancer Prev, 2017; 8(4):917-26.
Nik Abd Rahman NMA, Nurliyana MY, Afiqah MNFNN, Osman MA, Hamid M, Lila MAM. Antitumor and antioxidant effects of Clinacanthus nutans Lindau in $4 \mathrm{~T} 1$ tumor-bearing mice. BMC Complement Altern Med, 2019;19:340.

P'ng XW, Akowuah GA, Chin JH. Evaluation of the sub-acute oral toxic effect of methanol extract of Clinacanthus nutans leaves in rats. J Acute Dis, 2013; 2(1):29-32.

Pannangpetch $\mathrm{P}$, Laupattarakaseem $\mathrm{P}$, Kukongviriyapan V, Upa K, Bunkern K, Aromdee C. Antioxidant activity and protective effect against oxidative hemolysis of Clinacanthus nutans (Burm.f) Lindau. Songklanakarin J Sci Technol, 2007; 29(1):1-9.

Quah SY, Chin JH, Akowuah GA, Khalivulla SI, Yeong SW, Sabu MC. Cytotoxicity and cytochrome P450 inhibitory activities of Clinacanthus nutans. Drug Metab Pers Ther, 2017; 32(1):59-65.

Rahim MHA, Zakaria ZA, Mohd Sani MH, Omar MH, Yakob Y, Cheema MS, Ching SM, Ahmad Z, Kadir AA. Methanolic extract of Clinacanthus nutans exerts antinociceptive activity via the opioid/ nitric oxide-mediated, but cGMP-independent, pathways. Evid Based Complement Alternat Med, 2016; 2016:1494981.

Roslan NA, Kassim NII, Lim V, Jemon K. Subacute toxicity study of Clinacanthus nutans ethanolic extract in vivo. 2017. [ONLINE] Available via https://www.utm.my/ipsb/files/2017/08/SUBACUTETOXICITY-STUDY-OF-CLINACANTHUS-NUTANS.pdf. (Accessed 01 November 2020).

Sakdarat S, Shuyprom A, Na Ayudhya TD, Waterman PG, Karagianis G. Chemical composition investigation of the Clinacanthus nutans Lindau leaves. Thai J Phytopharm, 2006; 13(2):13-24.

Sakdarat S, Shuyprom A, Pientong C, Ekalaksananan T, Thongchai S. Bioactive constituents from the leaves of Clinacanthus nutans Lindau. Bioorg Med Chem, 2009; 17:1857-60.

Sarega N, Imam MU, Esa NM, Zawawi N, Ismail M. Effects of phenolic-rich extracts of Clinacanthus nutans on high fat and high cholesterol diet-induced insulin resistance. BMC Complement Altern Med, 2016a; 16:88

Sarega N, Imam MU, Ooi DJ, Chan KW, Esa NM, Zawawi $\mathrm{N}$, Ismail M. Phenolic rich extract from Clinacanthus nutans attenuates hyperlipidemia-associated oxidative stress in rats. Oxid Med Cell Longev, 2016b; 2016:4137908.

Satakhun S, Suwanborirux K, Lipipun Y, Suttisri R, Pummangura S. Chemical constituents of Clinacanthus nutans leaves. Thai J Pharm Sci, 2001; 25:38.

Shim SY, Aziana I, Khoo BY. Perspective and insight on Clinacanthus nutans Lindau in traditional medicine. Int J Integr Biol, 2013; 14(1):7.

Sriwanthana B, Chavalittumrong P, Chompuk L. Effect of Clinacanthus nutans on human cell-mediated immune response in vitro. Thai J Pharm Sci, 1996; 20:261-7.

Sulaiman ISC, Basri M, Chan KW, Ashari SE, Masoumi HRF, Ismail M. In vitro antioxidant, cytotoxic and phytochemical studies of Clinacanthus nutans Lindau leaf extracts. Afr J Pharm Pharmacol, 2015; 9:861-74.

Süntar I. Importance of ethnopharmacological studies in drug discovery: role of medicinal plants. Phytochem Rev, 2020; 19:1199-209.

Teoh PL, Cheng AYF, Liau M, Lem FF, Kaling PG, Chua FN, Cheong BE. Chemical composition and cytotoxic properties of Clinacanthus nutans root extracts. Pharm Biol, 2017; 55(1):394- 401.

Teshima KI, Kaneko T, Ohtani K, Kasai R, Lhieochaiphant S, Picheansoonthon C, Yamasaki K. Sulfur-containing glucosides from Clinacanthus nutans. Phytochem, 1998; 48:831-5.

Thongrakard V, Tencomnao T. Modulatory effects of Thai medicinal plant extract on proinflammatory cytokines-induced apoptosis in human keratinocyte HaCaT cells. Afr J Biotechnol, 2013;9:4999-5003.

Tsai HD, Wu JS, Kao MH, Chen JJ, Sun GY, Ong WY, Lin TN. Clinacanthus nutans protects cortical neurons against hypoxia-induced toxicity by downregulating HDAC1/6. Neuromolecular Med, 2016; 18(3):274-82. 
Tu SF, Liu RH, Cheng YB, Hsu YM, Du YC, El-Shazly M, Wu YC, Chang FR. Chemical constituents and bioactivities of Clinacanthus nutans aerial parts. Molecules, 2014; 19:20382-90.

Tuntiwachwuttikul P, Pootaeng-on Y, Phansa P, Taylor WC. Cerebrosides and a monoacylmonogalactosyglycerol from Clinacanthus nutans. Chem Pharm Bull, 2004; 52(1):27-32.

Vachirayonstien T, Promkhatkaew D, Bunjob M, Chueyprom A, Chavalittumrong P, Sawanpanyalert P. Molecular evaluation of extracellular activity of medicinal herb Clinacanthus nutans against herpes simplex virus type-2. Nat Prod Res, 2010; 24(3):236-45.

Wanikiat P, Panthong A, Sujayanon P, Yoosook C, Rossi AG, Reutrakul V. The anti-inflammatory effects and the inhibition of neutrophil responsiveness by Barleria lupulina and Clinacanthus nutans extracts. J Ethnopharmacol, 2008; 116:234-44.

Yahaya R, Dash GK, Abdullah MS, Mathews A. Clinacanthus nutans (Burm. f.) Lindau: an useful medicinal plant of South East Asia. Int J Pharmacogn Phytochem Res, 2015; 7(6):1244-50.

Yong YK, Tan JJ, Teh SS, Mah SH, Cheng CE, Chiong HS, Ahmad Z. Clinacanthus nutans extracts are antioxidant with antiproliferative effect on cultured human cancer cell lines. Evid Based Complement Alternat Med, 2013; 2013:462751.

Yuann JMP, Wang JS, Jian HL, Lin CC, Liang JY. Effects of Clinacanthus nutans (Burm.f) Lindau leaf extracts on protection of plasmid DNA from riboflavin photoreaction. MC-Trans Biotechnol, 2012; 4(1):e5.

Zakaria Y, Lim WY, Nik Hassan NF. Anti-cancer effects of Clinacanthus nutans extract towards human cervical cancer cell line, HeLa. J Biomed Clin Sci, 2017; 2(1):11-9.

Zulkipli IN, Rajabalaya R, Idris A, Sulaiman NA, David SR. Clinacanthus nutans: a review on ethnomedicinal uses, chemical constituents and pharmacological properties. Pharm Biol, 2017; 55(1):1093-113.

How to cite this article:

Teoh PL. A minireview on phytochemical and medicinal properties of Clinacanthus nutans. J Appl Pharm Sci, 2021; 11(06):015-021. 